\title{
MAJOR MAXILLOFACIAL INJURIES
}

\author{
Iain Hutchison, Michael Lawlor, David Skinner
}

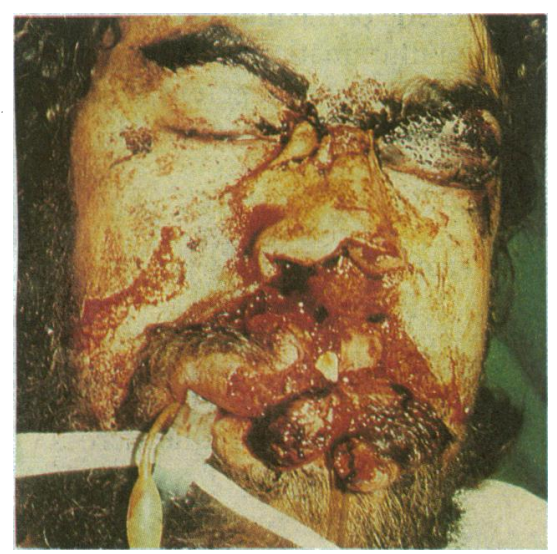

The multiply injured patient may have injuries of the face and neck that are life threatening or sufficiently serious to require specialist advice and management. In the initial assessment such patients may present with airway obstruction or hypovolaemic shock due to profuse and continuous bleeding from the facial skeleton or its surrounding soft tissues. The resuscitation team must be aware of these problems, know which specialists to call and when to call them, and be able to initiate manoeuvres to prevent the demise of the patient before the arrival of the specialist.

The first priority of the resuscitation team is to secure and maintain an airway, yet this action transgresses the site of maxillofacial trauma, which may be littered with broken teeth and dentures, bits of fractured bone, and macerated soft tissue.

\section{Management of the airway}

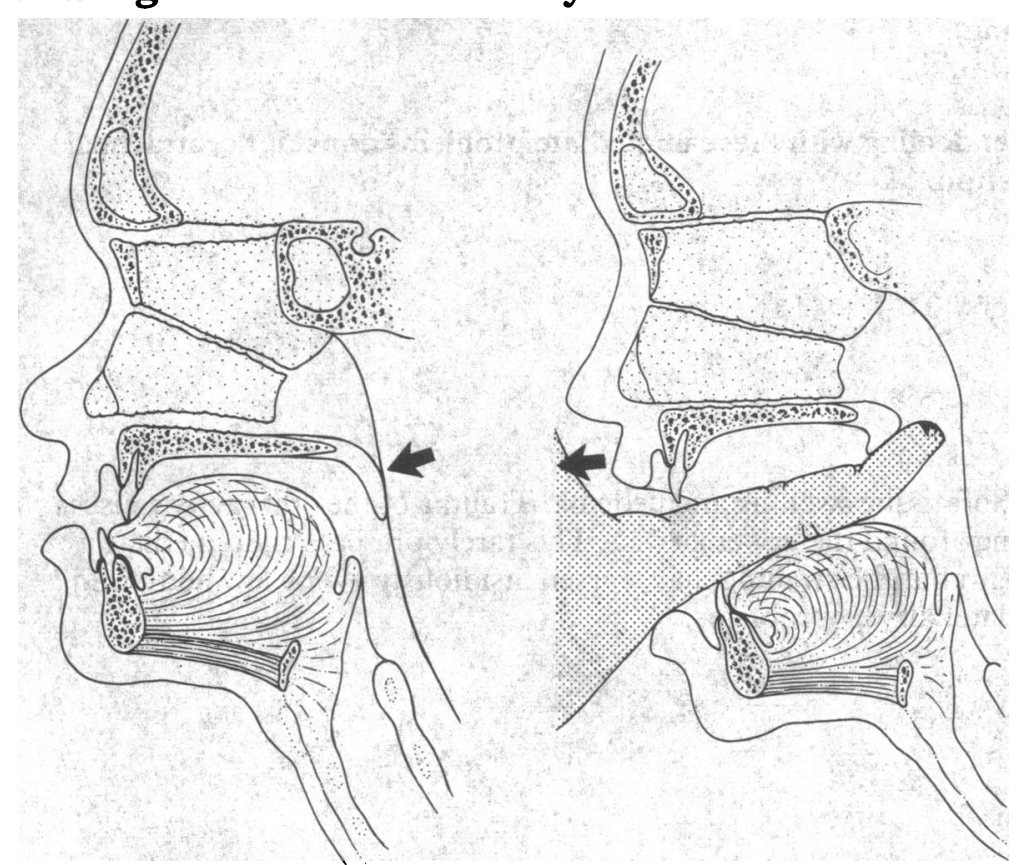

(Left) Fractured maxilla with posterior displacement, causing obstruction of the nasopharynx (arrowed). (Right) Fractured maxilla disimpacted and pulled forward to clear airway.

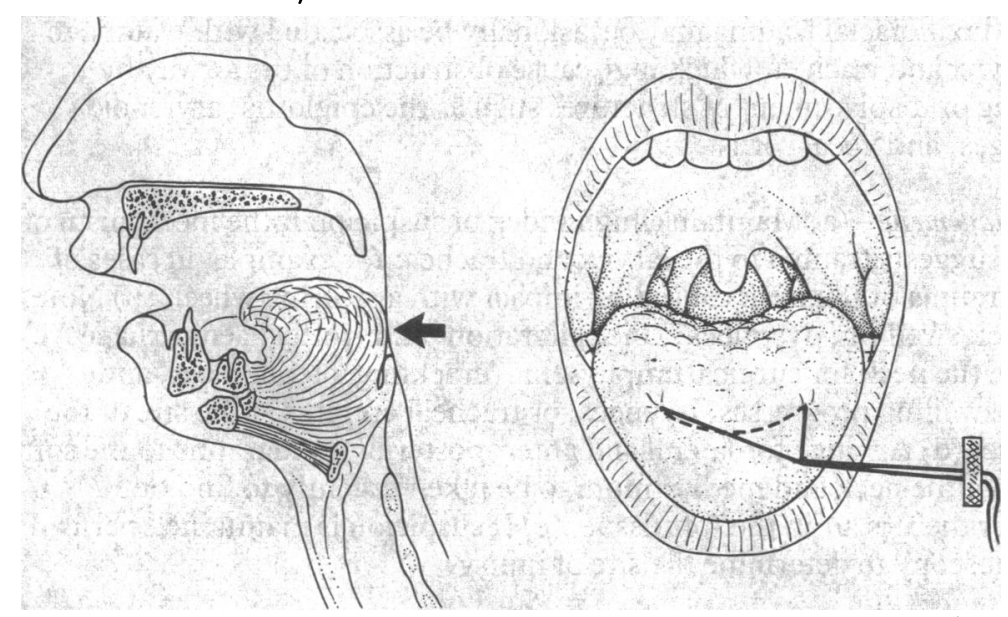

Six specific problems associated with maxillofacial trauma may affect the airway:

(1) A fractured maxilla may be displaced posteroinferiorally along the inclined plane of the base of the skull, blocking the nasal airway.

Management-Disimpact by pulling the maxilla forward with the index and middle fingers in the mouth behind and above the soft palate and with the thumb on the region of the incisors.

(2) The tongue may lose its anterior insertion in patients with a bilateral anterior mandibular or symphyseal fracture. It may then drop back in a supine patient, blocking the oropharynx.

Management-Insert a deep traction suture ( 0 gauge black silk) transversely through the dorsum of the tongue and tape the suture on to the side of the face; or, if no suture is available, pull the tongue forward by using a towel clip or pull the mandible forward manually. 


\section{Indications for chest radiography or bronchoscopy, or both}

- A foreign body is unaccounted for

- Cyanosis, tachypnoea, tachycardia, and respiratory distress

- Deterioration in $\mathrm{P}_{\mathrm{a}} \mathrm{O}_{2}$

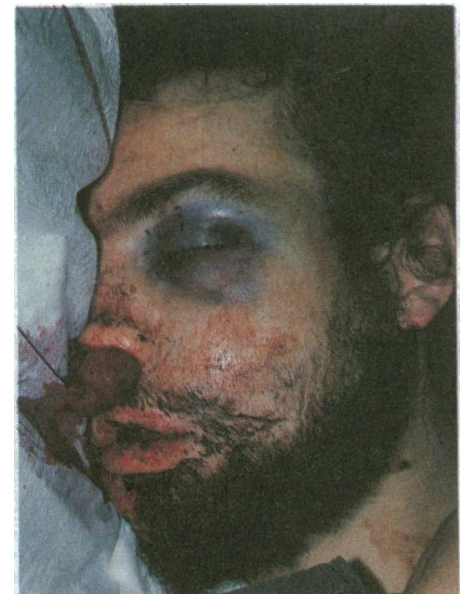

Life threatening haemorrhage from a closed bony injury of the maxilla.

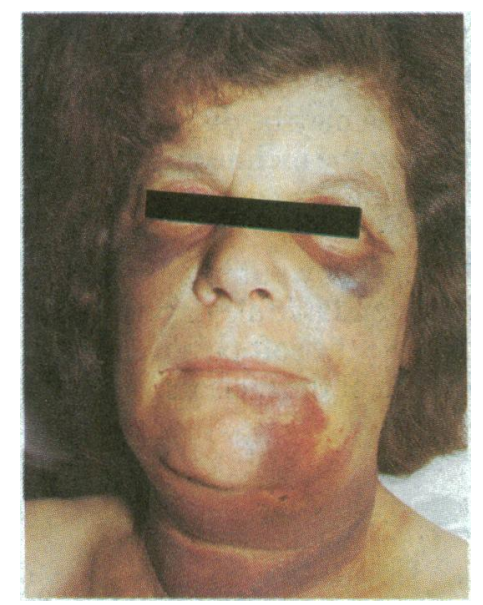

Haematoma and oedema of the neck and floor of the mouth caused by a fractured mandible.

\section{Management of injuries of the larynx and trachea}

- If the injury is above the larynx

-Perform cricothyroidotomy

- If the injury is at the level of the larynx and is incomplete

- Experts may pass an endotracheal tube -Otherwise, seek specialist opinion for tracheostomy

- If the injury is at the level of the larynx and is complete

-Seek specialist opinion for tracheostomy

- If the injury is in the trachea, below the potential tracheostomy site

-Refer urgently to a thoracic surgeon
(3) Teeth, dentures, bone fragments, vomitus, haematoma, and other foreign bodies may block the airway at any site from the oral cavity through the oropharynx, larynx, and trachea down to the bronchi, especially the right main bronchus.

Management-(a) Clear the oral cavity by using a gloved finger inserted laterally (just inside the cheek) to the back of the mouth, then hook the finger medially and forward to pull debris out of the mouth. (If the finger is pushed centrally foreign bodies may be pushed further down the airway.) (b) Repeat this manoeuvre from the opposite side of the mouth. (c) Use a large bore sucker (plastic yankauer) and good illumination to aspirate the oral cavity. (d) Use the laryngoscope and sucker (ignoring potential pain from mandibular fractures) to examine and clean the oropharynx and larynx.

(4) Haemorrhage may result from several causes:

(i) Distinct vessels in open wounds.

Management - Insert $5 \mathrm{~cm}$ ribbon gauze or gauze swabs as a firm compressed pack into the open wound to achieve pressure, request cross matching of blood, and arrange for definitive treatment.

(ii) The nose, as a result of damage to the anterior or posterior ethmoidal vessels or the terminal portion of the maxillary artery (see management of bleeding).

After dealing with these immediate problems consider orotracheal intubation.

(5) Soft tissue swelling and oedema. Trauma of the oral cavity causes swelling around the upper airway. This rarely presents an immediate problem, but the swelling may worsen insidiously over a few hours and cause later airway problems.

(6) Maxillofacial trauma may occasionally be associated with trauma to the larynx and trachea, which may cause obstruction of the airway by swelling or displacement of structures such as the epiglottis, arytenoid cartilages, and vocal cords.

Management - (a) Maintain a high index of suspicion if the mechanism of injury suggests trauma to the larynx and trachea: for example, in cases of blunt trauma of the neck caused by impact with a steering wheel. (b) Note any neck swelling, dyspnoea, voice alteration, and frothy haemorrhage. (c) Palpate the neck for surgical emphysema (crackling), tenderness, and, before swelling progresses, laryngeal or tracheal crepitus at the site of the fracture. (d) Arrange for lateral and anteroposterior radiographs to the soft tissues of the neck and mediastinum to be taken urgently to find out whether there is air in the soft tissue. (e) If suspicion is maintained perform bronchoscopy to determine the site of injury. 


\section{Management of bleeding}

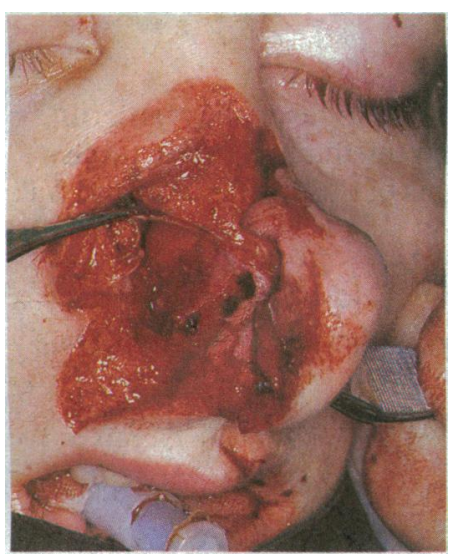

Apparently simple nasal soft tissue injury, which on exploration required extensive repair.

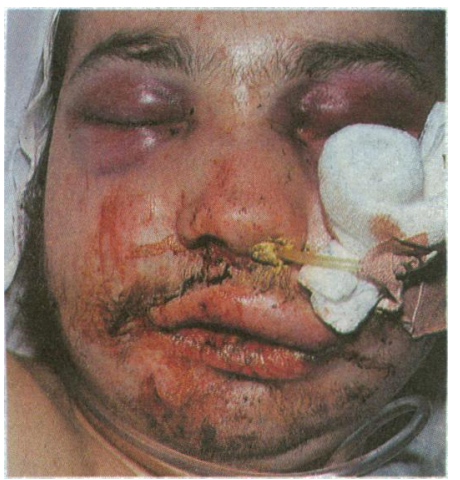

Major

haemorrhage caused by closed maxillofacial trauma, treated by anterior and posterior nasa packing.

\section{Procedure for anterior and posterior nasal packing}

(1) Insert 12/14 G Foley catheters with $20 \mathrm{ml}$ balloons into the nose

(2) Inflate balloons when the tip of the catheter is in the postnasal space

(3) Pull back the catheter until the balloon occludes against the choana at the back of the nose

(4) Tape the catheters under tension to the side of the face

(5) Insert bismuth iodoform paraffin paste $5 \mathrm{~cm}$ ribbon gauze packs into the nose in front of the balloon and Foley catheter

\section{Secondary survey}

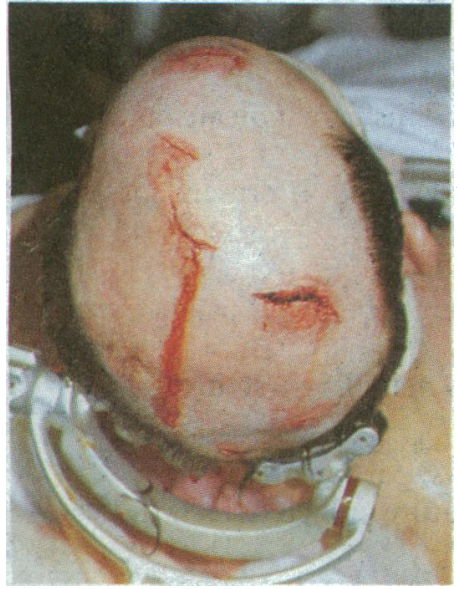

Underneath this apparently minor scalp injury was a fractured skull.

\section{Soft tissues}

Although the scalp, face, and neck have an excellent blood supply, extensive superficial lacerations in this region are not always accompanied by blood loss of such quantity that a transfusion is required. Conversely, small puncture wounds to the skin that scarcely seem to need suturing may cause life threatening haemorrhage if they involve a moderate size artery such as the facial artery or superficial temporal artery. The danger lies in overlooking the continuous trickle of fresh blood from the puncture wound.

Management-(a) Assess wounds regularly for blood loss. (b) If haemorrhage continues explore the wounds and clip or ligate bleeding vessels. (c) Extend puncture wounds along natural skin crease lines to locate bleeding vessels. (d) If profuse bleeding occurs from a neck wound, consider whether there is enough time for arteriography, check arm pulses, extend the wound to expose the major vessels in the neck (usually along the anterior border of the sternomastoid), control the bleeding, and assess damage. Small vessels off the external carotid artery may be ligated. Large arteries (for example, the carotid and subclavian arteries) usually require repair. It is possible to ligate one external jugular vein without untoward effect, and it may be possible to ligate one common carotid artery without causing a stroke.

\section{Bone}

Significant haemorrhage also occurs occasionally in patients with closed injuries to the bony structures of the middle third of the face - that is, the maxilla, nose, and ethmoids. This presents as a steady flow of blood from the nose and oral cavity and bleeding into the soft tissues of the face, producing profound cheek swelling with a shiny, tense skin.

Two problems exist:

(i) Failure to recognise the extent of blood loss and subsequent development of a coagulopathy.

(ii) An inability to define the source of the arterial bleeding as fractures of the middle third face are usually bilateral with disruption of the nasal septum. Therefore, haemorrhage from one side manifests equally at both nostrils.

Management--Exclude the possibility of bleeding from the base of skull by palpating the pharyngeal wall with your index finger through the mouth for tears and fractures. (b) Insert anterior and posterior nasal packs.

Once the airway has been secured and haemorrhage arrested the definitive management of soft tissue and bone trauma of the face and neck may be deferred until life threatening neurosurgical, thoracic, abdominal, and neurovascular limb injuries have been dealt with. It may be appropriate, however, to perform simultaneous procedures or even combined operations, particularly when cranial trauma is combined with facial trauma.

\section{Examination}

(1) Expose the affected area by cleaning all wounds and the face and scalp with Savlon $(0 \cdot 15 \%$ cetrimide $)$. Do not discard any loose bone or soft tissue fragments.

(2) Examine the scalp for lacerations and bruises, not forgetting the back of the scalp if it is possible to move the patient - that is, if a cervical spinal injury has been excluded or the cervical spine is protected by a collar. 


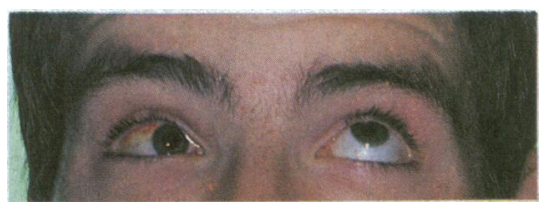

Limitation of upward gaze denoting an orbital floor fracture.

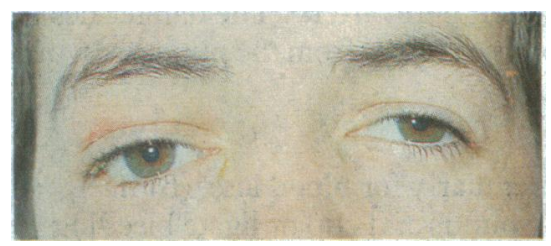

Proptosis and depression of right pupillary level due to fractured orbital roof and intraorbital haematoma.

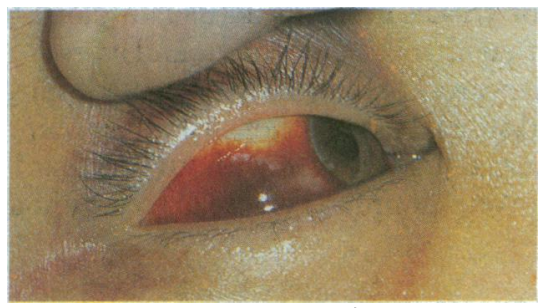

Subconjunctival ecchymosis.

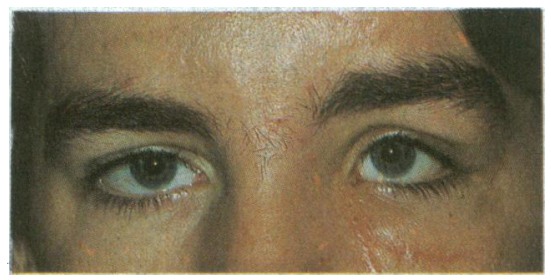

Left medial canthal damage with characteristic almond shaped palpebral fissure and increased intercanthal distance.

\begin{tabular}{|c|c|}
\hline \multicolumn{2}{|c|}{$\begin{array}{l}\text { Indications of bleeding from the } \\
\text { ears }\end{array}$} \\
\hline Site & Indication \\
\hline $\begin{array}{l}\text { Anterior wall of the } \\
\text { external auditory } \\
\text { meatus }\end{array}$ & $\begin{array}{l}\text { Fracture of the } \\
\text { condylar neck of the } \\
\text { mandible }\end{array}$ \\
\hline $\begin{array}{l}\text { Posterior wall or } \\
\text { middle ear }\end{array}$ & $\begin{array}{l}\text { Fracture of the base of } \\
\text { the skull in the } \\
\text { middle cranial fossa }\end{array}$ \\
\hline $\begin{array}{l}\text { Ecchymosis behind } \\
\text { the ear (Battle's } \\
\text { sign) }\end{array}$ & $\begin{array}{l}\text { Probable middle } \\
\text { cranial fossa } \\
\text { fracture }\end{array}$ \\
\hline
\end{tabular}

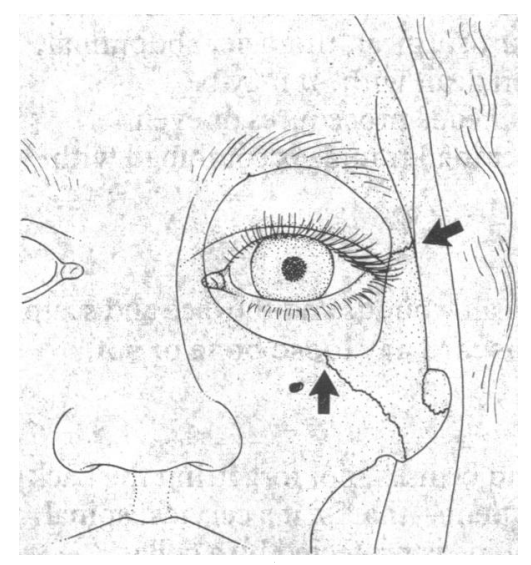

Palpate frontozygomatic and zygomatic maxillary sutures for pain and separation.
(3) Examine the eyes for:

- Visual acuity-can the patient count fingers? Can he or she read print?

- Limitation of eye movements, diplopia, and unequal pupillary levels.

If one or more of these is present suspect trauma of the orbital floor and wall with entrapment of periorbital tissues.

- Direct, consensual, and accommodation reflexes. Examination of these may help detect a rise in intracranial pressure, but be aware of false positive signs caused by trauma to the globe resulting in post-traumatic mydriasis and retrobulbar haemorrhage.

- Proptosis (or exophthalmos). This suggests haemorrhage within the orbital walls.

- Enophthalmos. This suggests fracture of the orbital wall (at the floor or medial wall).

- Periorbital swelling. If this is present suspect a fracture of the zygoma or maxilla.

- Subconjunctival ecchymosis. If this is present suspect direct trauma to the globe or a fractured zygoma.

Examine the anterior chamber and fundus for evidence of direct trauma and raised intracranial pressure.

(4) Examine the nose for:

- Deformity, pain, mobility, and difficulty in breathing.

- Bleeding and leakage of cerebrospinal fluid. If present suspect anterior cranial fossa fracture of the cribiform plate. Do not pass a nasal endotracheal tube or nasogastric tube. Give prophylactic sulphonamides or chloramphenicol to prevent meningitis.

Measure the intercanthal distance. If it is $>3.5 \mathrm{~cm}$ suspect nasoethmoidal fracture.

(5) Examine the ears for bleeding and leakage of cerebrospinal fluid.

(6) Examine the soft tissues for:

- Sensory (V nerve) (for example, of the upper or lower lip) and motor (VII nerve) deficit - this may have a peripheral or central cause. Consider this in relation to other injuries.

- Surgical emphysema around the eyes and on the face. This suggests continuity between sinuses and face due to facial fracture. To avoid emphysema instruct patients not to blow their nose. (Surgical emphysema in the face should be distinguished from that in the neck, which is caused by trauma to the larynx, trachea, or lungs)

- Venous engorgement of the face. If present suspect trauma of the major vessels in the thorax or neck.

- Pooling of tears and leakage from the eye. This may indicate damage to the lacrimal apparatus.

- Leakage of pink or clear fluid from a facial wound. If present suspect damage to the parotid duct.

(7) Examine the face for lengthening bilateral swelling, "panda eyes," and dish face deformity.

If any of these are present suspect bilateral maxillary fracture.

(8) Palpate around the orbit for step defects, particularly at the frontozygomatic and zygomaticomaxillary sutures. Such defects indicate fracture to the zygmota or maxilla.

(9) Palpate the mandible externally from the condyle and along the lower border for tenderness, step defects, and crepitus. 


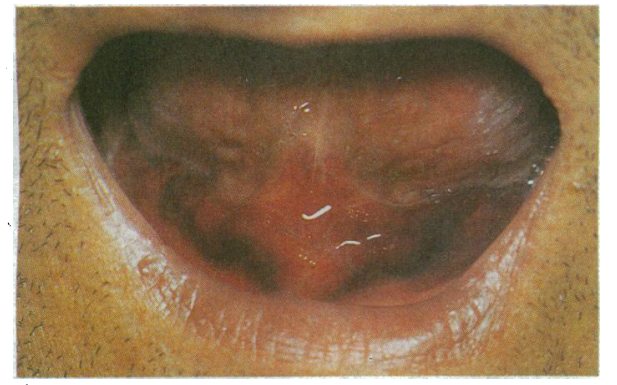

Sublingual haematoma caused by mandibular fracture.

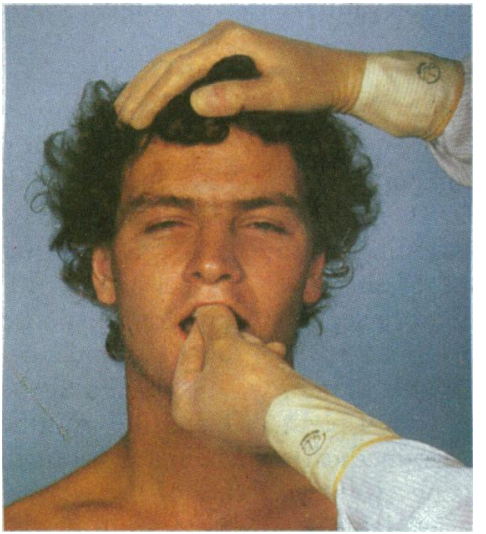

Pull on the anterior maxilla while supporting the frontal bone to show movement of the maxilla on the base of the skull, indicating maxillary fracture.
(10) Examine intraorally for haematoma (especially under the tonguethis indicates mandibular fracture), lacerations, bleeding, loose teeth, broken teeth and dentures, mobile jaw segments, abnormal alignment of the jaw and step defects, and teeth meeting prematurely.

(11) Using both hands palpate the middle third of the face for mobility. Place the thumb and fingers of the right hand on either side of the premaxillary teeth (with the thumb in front and the index finger on the palatal side). Place the palmar surface of the left hand across the forehead. Pull the premaxillary segment forward gently and see whether nose or cheek bones move, indicating a maxillary fracture at the Le Fort I, II, or III level.

(12) Good quality maxillofacial radiographs help in the definitive planning of treatment. The radiologist will decide which views are appropriate.

\section{Conclusion}

Mr Iain Hutchison, FRCS, and Mr Michael Lawlor, FFDRCSI, are consultants in maxillofacial surgery, St Bartholomew's Hospital, London. Mr David Skinner, FRCS, is consultant in accident and emergency medicine, St Bartholomew's Hospital.

The ABC of Major Trauma has been edited by $\mathrm{Mr}$ David Skinner, FRCS; Mr Peter Driscoll, FRCS; and Mr Richard Earlam, FRCS.

The photographs of general facial trauma and limitation of eye movements were provided by Mr D R James, those of haemorrhage by Mr J Attenborough, that of proptosis by

Mr R Haskell, and that of oedema by Mr R Juniper. The line drawings were prepared by the department of education and medical illustration services, St Bartholomew's Hospital, London.
Major maxillofacial injuries may occur in isolation or in combination with other injuries. They pose problems because they are intimidating and obstruct access to the airway. Rarely, they may be the cause of life threatening haemorrhage, which is often overlooked.

The definitive management of soft tissue and bone injuries of the face and neck can usually be deferred while life threatening thoracic, abdominal, and neurological injuries are dealt with. It may be appropriate, though, for the maxillofacial surgeon to help the anaesthetist and perform a fuller assessment, wound toilet, and preparatory procedures while the patient is anaesthetised. Combined procedures with specialists such as neurosurgeons may also be indicated.

\section{THE MEMOIR CLUB}

Looking, then, at the immensities of the universe we can easily see why we are overcome by magnitude, astonished by complexity, or bewildered by the effort to imagine what such things as "infinite density" or "the expanding universe" might mean in terms of our own experience. We are prepared to accept not only that every mystery may not yet have been revealed to us but that there are many things we might not be able to understand even if some supernatural being were to attempt an explanation. To think that there may be more things in heaven and earth than we are programmed to appreciate is a small concession in humility to temper a grand endeavour.

However, when we tackle matters of less stupendous moment but nevertheless involving great complexities of tissue or human relationships, development, and control, we are not so amenable and tend to become restless if the dawn of understanding seems slow in breaking. We are here far less willing to accept that lack of progress may be due to inadequate mental equipment, that we may not yet have acquired sufficient evidence, or merely that we are seeking answers to impossible questions. We can be too stupid, too ill informed, too lacking in imagination, or merely on the wrong tack. We may accept that organisational problems in biology are bound to be complicated but are less willing to admit that they may not be resolvable by those simple solutions we expect to find for them. They have to be tackled piecemeal, they need to be investigated by trial and error, they are not easily understood just because their field of operation is small. Paul Weiss wrote: "A living system is no more adequately characterised by an inventory of its material constituents, such as molecules, than the life of a city is described by the list of names and numbers in a telephone book."

From Not a Moment to Lose by David Smithers. Published under the BMF's Memoir Club imprint. ISBN 072790278 4. Price: Inland £14.95; abroad $£ 17.50$. BMA members: Inland £13.95; abroad £16.50. 